\title{
Cotrimoxazole - optimal dosing in the critically ill
}

\author{
Glen R Brown
}

\begin{abstract}
The optimum dosage regimen for cotrimoxazole in the treatment of life threatening infections due to susceptible organisms encountered in critically ill patients is unclear despite decades of the drug's use. Therapeutic drug monitoring to determine the appropriate dosing for successful infection eradication is not widely available. The clinician must utilize published pharmacokinetic, pharmacodynamic, and effective inhibitory concentration information to determine potential dosing regimens for individual patients when treating specific pathogens. Using minimum inhibitory concentrations known to successfully block growth for target pathogens, the pharmacokinetics of both trimethoprim and sulfamethoxazole can be utilized to establish empiric dosing regimens for critically ill patients while considering organ of clearance impairment. The author's recommendations for appropriate dosing regimens are forwarded based on these parameters.
\end{abstract}

Keywords: Cotrimoxazole; Trimethoprim; Sulfamethoxazole; Pharmacokinetics; Pharmacodynamics

\section{Review}

Cotrimoxazole, the combination of trimethoprim (TMP) and sulfamethoxazole (SMX), is frequently required for the treatment of critically ill patients with infections caused by sensitive pathogens, such as Pneumocystis jovenii or Stenotrophomonas maltophilia. As with other antibiotics, TMP/SMX must be given in a sufficient dose at a proper frequency to produce adequate concentrations at the site of infection for successful eradication of the pathogen. TMP/ SMX also has concentration-dependent toxicities, necessitating avoidance of excessive dosage. The determination of the appropriate dosing regimen requires optimum application of the drug's pharmacokinetics and pharmacodynamic characteristics. Data from clinical trials of various dosages of TMP/SMX in the critically ill population are generally lacking, forcing the clinician to prescribe the drug without clear knowledge of the appropriate regimen. This paper will review the available pharmacodynamic and pharmacokinetic data necessary for the clinician to determine the optimum dosage of TMP/SMX for selected infections in the critically ill.

Relevant electronic databases of published literature (Embase, Medline) containing studies of the pharmacokinetics, pharmacodynamics, and inhibitory concentrations of TMP/SMX were searched to end date of 16 September 2013. References of selected manuscripts were reviewed for

Correspondence: gbrown@providencehealth.bc.ca

Pharmacy Department, St. Paul's Hospital, 1081 Burrard St, Vancouver, BC V6Z 1Y6, Canada relevant citations. References in tertiary information sources, and the author's personal information files were searched for relevant data. The preliminary search yielded few studies focused specifically on the critically ill population. Therefore, studies outlining the pharmacokinetics in normal and altered organ clearance populations (renal and/ or liver impairment); the pharmacodynamics of TMP/SMX in any setting; and the minimum inhibitory concentrations, determined either in vitro or in vivo, were selected. Data from the selected publications were reviewed to allow an assessment of the applicability to the critically ill population and to determine potential dosing regimens for specific pathogens in critically ill patients.

\section{Pharmacokinetics}

The volume of distribution (Vd) for each drug has been determined in healthy subjects with TMP having a much larger volume of distribution than SMX based on differences in lipid solubility [1]. There are only very limited data available on the impact of critical illness on the $\mathrm{Vd}$ of the two drugs, despite the widely recognized changes that occur with other antibiotics. In critically ill patients requiring mechanical ventilation for Pneumocystis carinii pneumonia, the $\mathrm{Vd}$ of TMP was $1.6 \mathrm{~L} / \mathrm{kg}$ versus $1.4 \mathrm{~L} / \mathrm{kg}$ for non-ventilated patients, and the $\mathrm{Vd}$ for SMX was $0.5 \mathrm{~L} / \mathrm{kg}$ versus $0.4 \mathrm{~L} / \mathrm{kg}$ [2]. In trauma patients, although reporting low Acute Physiology and Chronic Health Evaluation II (APACHE II) scores of 1 to 24, the Vd of TMP was found to be $2.1 \mathrm{~L} / \mathrm{kg}$

\section{Springer}

(C) 2014 Brown; licensee Springer. This is an Open Access article distributed under the terms of the Creative Commons Attribution License (http://creativecommons.org/licenses/by/2.0), which permits unrestricted use, distribution, and reproduction in any medium, provided the original work is properly credited. 
and for SMX was $0.5 \mathrm{~L} / \mathrm{kg}$ [3]. No studies have reported the magnitude of change in $\mathrm{Vd}$ of the drugs in patients with septic shock requiring large volume resuscitation or vasopressors. Data are also lacking on the impact of obesity on the $\mathrm{Vd}$, and resulting dosing of the drug. Therefore, dosing regimens should be based on actual body weight.

Both TMP and SMX are eliminated from the body predominantly by renal excretion $[1,4]$. Approximately $20 \%$ of SMX is metabolized in the liver to $\mathrm{N}_{4}$-acetylsulfamethoxazole which is subsequently excreted in the urine [5]. $\mathrm{N}_{4}$-acetylsulfamethoxazole lacks relevant antibacterial activity [1]. The remainder of SMX is cleared by the kidney as unchanged drug [4]. The renal excretion of SMX is increased when the urine is alkaline [5]. Similarly, only a small portion of TMP (10 to 20\%) is metabolized by the liver to inactive metabolites, which are subsequently conjugated and excreted in the urine [1]. The remaining portion of TMP elimination is via renal secretion of unchanged drug [4]. Unlike SMX, TMP renal clearance is increased with acid urine [1].

Achievable concentrations for various dosages are described in Table 1. The commercially available tablet contains $80 \mathrm{mg}$ TMP with $400 \mathrm{mg}$ SMX (single strength) or $160 \mathrm{mg}$ TMP with $800 \mathrm{mg}$ SMX (double strength). An intravenous preparation is commercially available containing $16 \mathrm{mg}$ TMP with $80 \mathrm{mg}$ SMX per ml. Both intravenous (IV) and oral (PO) dosages of $15 \mathrm{mg} / \mathrm{kg} /$ day of TMP produced $\mathrm{Cmax}$ concentrations within the target range for treatment of Pneumocystis jovenii (5 to $8 \mathrm{mcg} / \mathrm{ml}$ ) [2,6]. Oral dosages of $20 \mathrm{mg} / \mathrm{kg} /$ day of TMP produced higher concentrations which resulted in a high incidence of toxicities [7]. For pathogens with lower target concentrations (see Target concentrations; Table 2), Cmin concentrations for TMP of above $2 \mathrm{mcg} / \mathrm{ml}$ can be maintained with a dosage of $160 \mathrm{mg}$ TMP twice daily.

\section{Renal dysfunction}

Despite the availability of TMP/SMX for a number of decades, published data on the optimum dosage of the drug in patients with renal impairment are unavailable, similar to many widely used treatments [18]. Early work demonstrated a linear relationship between the elimination rate of both unchanged SMX (weak correlation) or TMP (significant correlation) and renal function (as measured by inulin clearance) [8]. The strongest correlation between renal function and pharmacokinetics was seen with the clearance of SMX metabolites (inactive), while the unchanged SMX concentrations remained constant over a wide range of renal impairment $[8,19]$. These studies involved patients with renal impairment resulting in creatinine clearance rates of 3 to $72 \mathrm{ml} / \mathrm{min} / 1.73 \mathrm{~m}^{2}[8,19]$. Using the dosage recommended for normal renal function, similar concentrations of unchanged active SMX from patients with normal renal function were achieved in patients with severe renal impairment [8]. Others, however, have found the elimination of unchanged SMX to be related to renal function, with an estimation of the half-life possible via calculation:

$$
\mathrm{T} 1 / 2=39 \times(\mathrm{CrClml} / \mathrm{min})^{-0.29}[20]
$$

The total amount of SMX (unchanged and metabolites) recovered in the urine of patients with renal impairment remains similar to patients with normal renal function (approximately $80 \%$ of an oral dosage), but the portion of the drug remaining unchanged decreased as renal function decreased, suggesting increased metabolism as renal function deteriorates [8]. The magnitude of the increase in clearance can not be estimated clinically or from published literature, but may be of relevance in producing drug concentrations equivalent to patients with normal renal function. The lack of accumulation of active SMX with renal impairment has important therapeutic ramifications since the metabolite does not have antimicrobial activity. If the SMX dosage is reduced when treating patients with renal impairment, the concentration of the active unchanged SMX may decrease, since its clearance is not impaired and may even increase, and potentially compromise the therapeutic effect.

The correlation of renal function and TMP clearance has been verified by other investigators $[19,20]$. The elimination half-life of TMP has been found to approximate:

$$
\mathrm{T} 1 / 2=28 \times(\mathrm{CrClml} / \mathrm{min})^{-0.13}[20]
$$

Both unchanged drug and the conjugated metabolites of TMP will accumulate as renal function decreases unless a dosage reduction is implemented.

\section{Liver dysfunction}

The pharmacokinetics of both SMX and TMP are not altered significantly by liver impairment [5]. The half-life of both SMX and TMP was not prolonged, versus normal subjects, in patients with mild or severe liver dysfunction, although the characterization of the liver function was poorly defined [21].

The metabolism of SMX appears to be influenced by the activity of $\mathrm{N}$-acetyltransferase 2 (NAT2), with the existence of genetic polymorphism altering the activity of the enzyme [22]. Patients without the native NAT2*4 allele do not clear SMX as rapidly resulting in accumulation of drug and increased exposure [22]. However, the published research methodology does not describe the ability to differentiate active unaltered SMX from the various metabolites. Since they found a correlation between drug accumulation and creatinine clearance, the potential that the finding of increased exposure in patients without native NAT2 $* 4$ could be due to accumulation of inactive SMX metabolites. No data exist to describe the effect of critical illness on activity of NAT2 or the ramifications of dosing of patients with the 
Table 1 Pharmacokinetics of cotrimoxazole (TMP/SMX) in various non-critically ill populations with normal renal and liver function

\begin{tabular}{|c|c|c|c|c|c|c|c|c|c|c|c|c|}
\hline $\begin{array}{l}\text { Population } \\
\text { [Reference] }\end{array}$ & Gender & $\begin{array}{l}\text { Age } \\
\text { (year) }\end{array}$ & $\begin{array}{l}\text { Weight } \\
\text { (kg) }\end{array}$ & Dose & Route & Duration & $\begin{array}{l}\mathrm{Cmax} \\
\mathrm{mcg} / \mathrm{ml}\end{array}$ & $\begin{array}{l}\text { Tmax } \\
(\min )\end{array}$ & $\begin{array}{l}\mathrm{Cmin} \\
\mathrm{mcg} / \mathrm{ml}\end{array}$ & $\begin{array}{l}\text { Vd } \\
\text { (Liters/kg) }\end{array}$ & $\begin{array}{l}\text { T1/2 } \\
\text { (hours) }\end{array}$ & $\begin{array}{l}\text { Clearance } \\
(\mathrm{ml} / \mathrm{min} / \mathrm{kg})\end{array}$ \\
\hline \multirow[t]{2}{*}{ Normal [8] } & $1 \mathrm{~F} / 3 \mathrm{M}$ & 34 & 66 & 80 mg TMP & $\mathrm{PO}$ & Q12h $\times 9$ days & & & & 1.5 & 8.2 & \\
\hline & & & & 400 mg SMX & & & & & & 0.26 & 9.8 & \\
\hline \multirow[t]{2}{*}{ Normal [9] } & $\mathrm{N} / \mathrm{A}$ & 21 to 40 & N/A & 240 mg TMP & IV & Q12h $\times 7$ doses & 5.91 & 15 & 2.64 & & 16.5 & \\
\hline & & & & $1,200 \mathrm{mg}$ SMX & & & 178 & & 78 & & 14.1 & \\
\hline \multirow[t]{2}{*}{ Normal [7] } & $12 \mathrm{M}$ & 28 & 75.8 & 20.2 mg/kg/day TMP & $\mathrm{PO}$ & Q6h $\times 13$ doses & 13.6 & 114 & & 1.4 & 13.6 & 1.05 \\
\hline & & & & 101.1 mg/kg/day SMX & & & 372 & 156 & & 0.25 & 14.0 & 0.024 \\
\hline \multirow[t]{2}{*}{ Normal [6] } & $6 \mathrm{M}$ & 26.7 & 73.7 & 12.6 mg/kg/day TMP & $\mathrm{PO}$ & Q6h $\times 3$ days & 8.3 & 90 & 6.1 & 1.78 & 14.6 & 0.89 \\
\hline & & & & $63.3 \mathrm{mg} / \mathrm{kg} /$ day SMX & & & 247 & 108 & 199 & 0.27 & 14.0 & 0.02 \\
\hline \multirow[t]{2}{*}{ HIV PCP [10] } & $1 \mathrm{~F} / 22 \mathrm{M}$ & 24 to 75 & 59 & 15 to 22 mg/kg TMP & IV (15) & Q6h $\times 4$ to 6 days & & & 7.7 & & & \\
\hline & & & & 75 to $110 \mathrm{mg} / \mathrm{kg} \mathrm{SMX}$ & PO (8) & & & & 198 & & & \\
\hline \multirow[t]{2}{*}{ PCP [2] } & N/A & 37 & 67.6 & 16.1 mg/kg/day TMP & IV & Q6 to $8 \mathrm{~h} \times 2$ to 10 days & 7.9 & 15 & & 1.5 & 11.3 & 1.73 \\
\hline & & & & 80.5 mg/kg/day SMX & & & 186 & & & 0.4 & 14.3 & 0.34 \\
\hline Ventilated & $\mathrm{N} / \mathrm{A}$ & 37 & 68.5 & 14.7 mg/kg/day TMP & IV & Q6 to $8 \mathrm{~h} \times 2$ to 10 days & 8.1 & 15 & & 1.6 & 10.9 & 1.88 \\
\hline PCP [2] & & & & 73.4 mg/kg/day SMX & & & 163 & & & 0.5 & 15.5 & 0.40 \\
\hline \multirow[t]{2}{*}{ Oncology [11] } & $\mathrm{N} / \mathrm{A}$ & $\mathrm{N} / \mathrm{A}$ & $\mathrm{N} / \mathrm{A}$ & 150 mg/m² TMP & IV & Q8h $\times 24$ hours & 7.02 & 65 & 3.65 & & 9.60 & \\
\hline & & & & $750 \mathrm{mg} / \mathrm{m}^{2} \mathrm{SMX}$ & & & 148 & & 88 & & 10.7 & \\
\hline Infected & $6 \mathrm{~F} / 5 \mathrm{M}$ & 60 & 65 & 160 mg TMP & IV & Q8h $\times 4$ days & 8.8 & 60 & 5.6 & 0.72 & 11.3 & 1.13 \\
\hline Cancer [12] & & & & $800 \mathrm{SMX}$ & & & 105.6 & & 70.6 & 0.27 & 12.8 & 0.04 \\
\hline \multirow[t]{2}{*}{ Trauma [3] } & $2 \mathrm{~F} / 13 \mathrm{M}$ & 31 & 87 & 8 mg/kg/day TMP & IV & Q12h & & & & 2.1 & 9.8 & 2.8 \\
\hline & & & & 40 mg/kg/day SMX & & & & & & 0.51 & 8.4 & 0.75 \\
\hline
\end{tabular}

$\mathrm{M}$, male; F, female; Cmax, maximum concentration within the dosing interval; Tmax, time to reach maximum concentration; Cmin, minimum concentration within dosing interval.

Vd, volume of distribution; T1/2, calculated half-life; N/A, not available; PO, oral administration; IV, intravenous administration; PCP, Pneumocystis jovenii pneumonitis.

various polymorphisms. Since the individual patients' genetic makeup is not usually known at the time of initiating TMP/ SMX therapy, currently the clinician is unable to assess or consider the need for dosage adjustments.

\section{Dialysis}

Similar to findings in non-dialysis dependent renally impaired patients, unchanged SMX concentrations do not increase in patients with renal impairment sufficient to necessitate dialysis [8]. However, the concentrations of TMP and of SMX metabolites increased in dialysis-dependent patients compared to patients with severe non-dialysis dependent renal impairment [8]. Surprisingly, given the drug's prolonged use, only limited description of the effect of dialysis on removal of each drug during a dialysis session is available; none for critically ill patients. Pharmacokinetic evaluation in a single patient during a hemodialysis session suggested efficient removal of both antibiotics, with total (unchanged and metabolites) SMX clearance increasing approximately 3.5 -fold over non-dialysis periods (83.9 versus $24.4 \mathrm{ml} / \mathrm{min}$ ) [23]. Approximately $50 \%$ of total (unchanged and metabolites) SMX and TMP body stores was removed by a four hour dialysis with a $1 \mathrm{~m}^{2}$ cuprophane dialysis membrane at a blood flow rate of $200 \mathrm{ml} / \mathrm{min}$ and dialysate flow rate of $500 \mathrm{ml} / \mathrm{min}$ [24]. These limited data suggest that hemodialysis is effective in removing SMX metabolites and TMP. However, since active SMX does not accumulate with standard dosing in dialysis patients, the optimum dosing of the combination becomes challenging. Dosage reduction may compromise the activity of unchanged SMX while standard

Table 2 Target concentrations for selected pathogens

\begin{tabular}{llll}
\hline Organism & $\begin{array}{l}\text { Target } \\
\text { concentration } \\
\text { trimethoprim } \\
\text { (mcg/ml) }\end{array}$ & $\begin{array}{l}\text { Target } \\
\text { concentration } \\
\text { sulfamethoxazole } \\
\text { (mcg/ml) }\end{array}$ & Reference \\
\hline $\begin{array}{l}\text { Pneumocystis } \\
\text { jovenii }\end{array}$ & 5 to $8 \mathrm{Cmax}$ & 100 to $200 \mathrm{mcg} / \mathrm{ml} \mathrm{Cmax}$ & {$[13]$} \\
$\begin{array}{l}\text { Stenotrophomonas } \\
\text { maltophilia }\end{array}$ & $>6 \mathrm{Cmax}$ & $>60 \mathrm{Cmax}$ & [14] \\
$\begin{array}{l}\text { Burkholderia } \\
\text { pseudomallei }\end{array}$ & $\geq 2 \mathrm{Cmin}$ & $\geq 38 \mathrm{Cmin}$ \\
$\begin{array}{l}\text { Nocardia } \\
\begin{array}{l}\text { Methicillin-resistant } \\
\text { Staphylococcus }\end{array}\end{array}$ & $\geq 2 \mathrm{Cmin}$ & $\geq 38 \mathrm{Cmin}$ & {$[15]$} \\
$\begin{array}{l}\text { aureus } \\
\text { ESBL } \\
\text { Enterobacteriaceae }\end{array}$ & $\geq 2 \mathrm{Cmin}$ & $\geq 38 \mathrm{Cmin}$ & {$[17]$} \\
\hline
\end{tabular}

Cmax, Maximum concentration during dosing interval. Cmin, Minimum concentration during dosing interval. 
dosages will result in accumulation of potentially toxic SMX metabolites and TMP. A potential approach would be to provide full dosages for the first 24 to 48 hours with subsequent dosage reduction based on clinical response [25].

SMX and its metabolites are partially removed by continuous ambulatory peritoneal dialysis [5], although the amount cleared would be anticipated to be clinically insignificant $[23,26]$. Instillation of $2 \mathrm{~L}$ of $2.5 \%$ glucose peritoneal dialysis solution four times daily contributed only $7 \%$ of total TMP body clearance and $8 \%$ of unchanged SMX clearance in chronic CAPD patients [27]. SMX metabolites are similarly poorly removed by CAPD as demonstrated by a low clearance rate found with four times daily dwells [16]. Rapid cycling peritoneal dialysis at a rate of $3 \mathrm{~L} /$ hour efficiently (60\%) removed SMX, but had minimal effects on TMP clearance [28]. Hence, peritoneal dialysis should not be considered to reduce the potential for accumulation of either drug to toxic concentrations, and the remaining renal function of the patient should guide dosing.

Removal rates during continuous veno-venous hemodiafiltration $\left(1.8 \mathrm{~m}^{2}\right.$ high-flux polysulfone filter at blood flow rates of $180 \mathrm{ml} / \mathrm{min}$, dialysate flow rate of $1,500 \mathrm{ml} /$ hour and fluid replacement of $1,500 \mathrm{ml} /$ hour) produced clearance rates for both drugs similar or exceeding normal renal function [29]. Extended daily dialysis $\left(1.3 \mathrm{~m}^{2}\right.$ high flux polysulfone filter at blood flow rates of $140 \mathrm{ml} / \mathrm{min}$, dialysate flow of $170 \mathrm{ml} / \mathrm{min}$ for 440 minutes) resulted in substantial clearance of TMP, with less clearance of SMX, and no report of clearance of SMX metabolites [30]. These authors caution clinicians regarding dosing reduction during continuous veno-venous hemodiafiltration and the potential for such reduction to result in inadequate drug concentrations [30].

\section{Toxic concentrations}

The theoretical benefit of utilizing larger dosages of TMP/ SMX to ensure the adequacy of achievable concentrations at site of infection must be balanced against the real occurrence of side effects due to excessive drug concentrations (Table 3). Although some TMP/SMX toxicities are predictable, such as the development of hyperkalemia and type 4 renal tubule acidosis from TMP inhibition of sodium channels in the distal nephron, others can not be anticipated. Such unpredictable toxicities are thought to be concentration-related, based on the offending dosages and impaired clearance in many affected patients. However, the concentration required for development of specific toxicities is unknown since the majority of case reports of concentration-dependent toxicities do not have measured serum concentrations at the time of symptoms or signs. However, based on the dosage and the patients' size and renal function reported in published cases, concentrations required to produce the toxicity would be anticipated to equal or exceed those seen with therapy of $15 \mathrm{mg} / \mathrm{kg} /$ day of TMP. This threshold dosage is based on the only clinical
Table 3 Selected cotrimoxazole (TMP/SMX) toxicities and relationship to drug concentration

\begin{tabular}{ll}
\hline Idiosyncratic toxicity & Concentration dependent toxicity \\
\hline Allergic skin reaction [31] & Apraxia [32] \\
Cholestasis [33] & Delirium [34] \\
Hemolytic crisis [35] & Hyperkalemia [36] \\
Hepatitis [37] & Hypoglycemia [38] \\
Interstitial nephritis [39] & Aseptic meningitis [40] \\
Methemoglobinemia [41] & Metabolic acidosis [42] \\
MODS [43] & Myoclonus [44] \\
Pancreatitis [45] & Psychosis [46] \\
Parotitis [47] & Renal tubular obstruction [48] \\
Stevens-Johnson syndrome [49] & Tremor [50] \\
Thrombocytopenia [51] & \\
Torsades de pointe [52] & \\
\hline
\end{tabular}

MODS, Multi-organ dysfunction syndrome. Square-bracketed numbers indicate references.

trial reporting toxicities with various dosages where dosage regimens producing higher concentrations (Mean for Cmax of TMP $13.6 \mathrm{mcg} / \mathrm{ml} / \mathrm{SMX} 372 \mathrm{mcg} / \mathrm{ml}$ ) produced an unacceptable incidence of toxicity [7]. Given the large variety of concentration-related toxicities, the clinician can not utilize excessive dosages without exposing the patient to potential risk of toxicity. Similarly, the accumulation of SMX metabolites in renal failure (see Pharmacokinetics above) is anticipated to increase the potential for concentration-related toxicities. However, the balance between effective doses and doses that will produce toxicities with renal impairment is not clear. The truly idiosyncratic toxicities (those that occur at dosages tolerated by the vast majority of patients) cannot be predicted or avoided through dose manipulation.

\section{Pharmacodynamics}

Both TMP and SMX act by blocking steps in the production of metabolically active folate [53]. Sulfonamides act by blocking the production of dihydrofolate from precursor components ( $p$-aminobenzoate, pteridine, and glutamate) [54]. This inhibition is irrelevant for human metabolism since humans can utilize dihydrofolate absorbed from the diet while bacteria must manufacture the dihydrofolate from precursors. TMP works on a subsequent step of folate metabolism by competitively inhibiting dihydrofolate reductase, the enzyme responsible for production of the active tetrahydrofolate [54]. Humans are not adversely affected by the TMP-induced blockage of dihydrofolate reductase since this enzyme in bacteria is greater than 1,000-fold more sensitive than human dihydrofolate reductase. Therefore, at concentrations achieved with therapeutic dosages, two steps in folate metabolism within bacteria are blocked, while human metabolism is unaffected. 
Surprisingly, the determination of the pharmacodynamic parameter (concentration or time) most related to bacterial kill has not been clearly determined [55]. TMP/ SMX has variable bacteriostatic and bacteriocidal action. Early work suggested that TMP/SMX has bacteriocidal activity against gram positive organisms, such as Staphylococcus aureus [56]. What little available evidence evaluating concentration versus time killing suggests that TMP/ SMX has concentration-dependent activity against grampositive organisms, such as Staphylococcus aureus [54,57]. For gram-negative organisms, it has been hypothesized that TMP/SMX has concentration-dependent killing of E. coli, although supporting data are lacking [57]. Early investigations suggested only bacteriostatic activity with concentrations achievable in urine due to interaction with nutrients which inhibit the activity of the drugs [58]. Subsequent limited evaluation suggests that TMP/SMX is bacteriostatic against sensitive $E$. coli at concentrations of $2 \mathrm{mcg} / \mathrm{ml}$ TMP and $40 \mathrm{mcg} / \mathrm{ml} \mathrm{SMX,} \mathrm{supporting} \mathrm{time-}$ dependent killing [59]. However, others have shown that at TMP concentrations greater than $2 \mathrm{mcg} / \mathrm{ml}(>12 \mathrm{mcg} / \mathrm{ml}$ SMX) bacteriocidal activity can be detected [20].

For other organisms, the pharmacodynamics are even less clear. Limited evidence from Burkholderia pseudomallei treatment suggests concentration effects through achievable in vivo concentrations [60]. This concentration-dependent killing was not long standing, and converted to bacteriostatic effects when studied using time-kill methodology [60]. Only bacteriostatic activity could be demonstrated against Nocardia spp. at TMP/SMX concentrations of $3.4 / 17 \mathrm{mg} / \mathrm{L}$; a concentration achievable with a $7.5 \mathrm{mg} / \mathrm{kg} /$ day TMP dose) [61].

In summary, TMP/SMX possesses bacteriostatic activity, which is time dependent, with the potential for concentration dependent bacteriocidal activity for specific organisms, possibly in selected infected sites within the body. Since the pharmacodynamics are unclear, clinicians should select dosages that would be anticipated to produce adequate concentrations, as described by successful therapeutic studies, throughout the dosage interval.

\section{Target concentrations}

\section{Pneumocystis jovenii}

The target concentrations for inhibition of growth of Pneumocystis jovenii are thought to span a range of 5 to 8 $\mathrm{mcg} / \mathrm{ml}$ for TMP and 100 to $200 \mathrm{mcg} / \mathrm{ml}$ for SMX at the maximum (Cmax) concentrations of the dosing interval. This range is based on early clinical trials in non-HIV infected patients who had a worse outcome with doses which were unsuccessful in achieving such steady state Cmax concentrations [62-64]. Subsequent trials, again in non-HIV infected patients, demonstrated good clinical recovery when the TMP/SMX dosage was adjusted to achieve a TMP Cmax concentration above $5 \mathrm{mcg} / \mathrm{ml}$ [65].
Dosage regimens producing Cmax concentration within a range of 5 to $8 \mathrm{mcg} / \mathrm{ml}$ for TMP and 100 to $200 \mathrm{mcg} / \mathrm{ml}$ for SMX have been demonstrated to produce more rapid resolution of fever and improvement of alveolar-arterial oxygenation gradient than use of pentamidine [13]. These target concentrations also demonstrated improved survival when compared to use of pentamidine [13]. Dosage regimens producing higher concentrations (mean for Cmax of TMP $13.6 \mathrm{mcg} / \mathrm{ml} / \mathrm{SMX} 372 \mathrm{mcg} / \mathrm{ml}$ ) have been associated with an unacceptable incidence of toxicity [7]. These data suggest target Cmax concentrations within a range of 5 to $8 \mathrm{mcg} / \mathrm{ml}$ for TMP and 100 to $200 \mathrm{mcg} / \mathrm{ml}$ for SMX are optimal for Pneumocystis jovenii treatment.

\section{Stenotrophomonas maltophilia}

The target concentrations for eradication of Stenotrophomonas infections are unknown. The Clinical and Laboratory Standards Institute (CLSI) standard breakpoint for Stenotrophomonas sensitivity to TMP/SMX is $<2 \mathrm{mcg} / \mathrm{ml}$ for TMP and $38 \mathrm{mcg} / \mathrm{ml}$ for SMX [17]. Approximately 95\% of North American Stenotrophomonas maltophilia strains were sensitive using the CLSI breakpoint when assessed in the late 1990s [66]. However, other investigators have found that the minimum inhibitory concentration adequate to inhibit $90 \%$ $\left(\mathrm{MIC}_{90}\right)$ of isolates is as high as $4 / 76 \mathrm{mcg} / \mathrm{ml}$ [67], a concentration still achievable with oral dosing. Higher concentrations may be desirable based on an in vitro model that showed that Cmax concentrations of $6 / 60 \mathrm{mcg} / \mathrm{ml}$ were not bacteriocidal, only bacteriostatic [14]. Very high concentrations $(32 / 608 \mathrm{mcg} / \mathrm{ml})$ are required for bacteriocidal activity, a concentration not achievable or tolerated (see below) [67]. In light of the unlikelihood of achieving bacteriocidal concentrations with tolerable doses, serious Stenotrophomonas infections should be treated with alternative antibiotics, such as fluoroquinolones or combinations of betalactam or fluoroquinolones with TMP/SMX [68]. However, infections caused by isolates with lower MICs can be successfully treated, although the optimum serum concentrations have not yet been determined.

\section{Burkholderia pseudomallei (Melioidosis)}

Burkholderia pseudomallei is the causative organism of potentially fatal respiratory infections. The CLSI breakpoints for B. pseudomallei are $<2 \mathrm{mcg} / \mathrm{ml}$ for TMP and $<38 \mathrm{mcg} / \mathrm{ml}$ for SMX [15]. Alternative antibiotics with more favorable MIC and pharmacodynamics, such as cephalosporins or carbapenems, should be considered for acute treatment of serious infections [69]. However, for eradication therapy requiring up to three months of continuous treatment, oral TMP/SMX is an effective and attractive option based on the ease of administering the drug versus parenterally administered alternatives [69]. Based on pharmacodynamic evaluation for B. pseudomallei, TMP/SMX was found to be bacteriostatic, so the concentration should be targeted to 
correspond to the individual isolate MIC [60]. Maintaining the serum concentration above the MIC for $60 \%$ of the dosing interval or a 24 hour Area under the concentration curve/MIC ratio of greater than 25 have been suggested as a target pharmacokinetic index [60]. This recommendation has not been tested in a clinical trial evaluating patient outcome. Alternatively, using the dosage of 160/800 mg twice daily for three months has been shown to be effective in eradication of the infection [70].

\section{Nocardia spp.}

Nocardia frequently produces life-threatening infections in immunocompromized patients, particularly following solidorgan transplantation. The breakpoint for susceptibility for Nocardia spp. is $\leq 2 / 38 \mathrm{mg} / \mathrm{L}$ TMP/SMX [15]. Resistant strains of various Nocardia species are frequently encountered $[16,71]$. The $\mathrm{MIC}_{90}$ of many of the resistant strains is 4/76 mg/L [16], a concentration only achievable throughout the dosing interval with high dose TMP/SMX.

\section{Methicillin-resistant Staphylococcus aureus (MRSA)}

The CLSI breakpoint for methicillin-resistant Staphylococcus aureus (MRSA) is identical to that of methicillin-sensitive strains $\leq 2 / 38 \mathrm{mcg} / \mathrm{ml}$ [17]. The prevalence of resistance of MRSA to TMP/SMX varies greatly throughout the world, and may also vary over time within individual institutions, possibly reflecting frequency of TMP/SMX use [72]. If an isolate of MRSA is sensitive to TMP/SMX, the antibiotic is an attractive treatment option. Clinical trials demonstrating clinical efficacy for TMP/SMX in MRSA infections are limited [73]. For an isolate deemed sensitive utilizing the CLSI breakpoint, achievable concentrations with traditional dosing would be expected to be successful in eradicating the pathogen. Small clinical trials have shown such success in treating MRSA bacteremia and other infections, although drug concentrations were not measured [74,75]. However, recent data suggesting that TMP/SMX has negligible effect against intracellular MRSA may limit the clinical utilization of the antibiotic [76].

\section{Enterobacteriaceae - extended-spectrum $\beta$-lactamase- producing (ESBL) Enterobacteriaceae}

TMP/SMX is not altered by beta-lactamases due to the physical structure of each of the antibiotics composing TMP/SMX. However, the majority of organisms which possess the capability to produce ESBLs have also acquired concurrent mechanisms for resistance to TMP/SMX [77]. For example, only approximately $26 \%$ of $E$. coli ESBLproducing strains were sensitive to TMP/SMX in a collection of isolates from across Canada in 2007 to 2009 [78]. Exceeding the Standard CSLI breakpoint concentrations $(\leq 2 / 38)$ would theoretically be adequate for eradication of sensitive organisms (CSLI). However, evidence supporting the effectiveness or inadequacy of achieving clinical cure when using TMP/SMX for ESBL-producing infections is lacking.

\section{Dosing recommendations in the critically ill}

The clinician is frequently placed in a position of uncertainty regarding the MIC of the infecting organism, and the appropriate dose to achieve the target concentrations for optimal pharmacodynamics, and resulting efficacy. Clinical trials to demonstrate the optimal dosing regimens, as discussed above, are generally lacking. The benefit of prospective therapeutic drug monitoring of TMP/ SMX concentrations in critically ill patients has not been evaluated in the published literature. Intuitively, therapeutic drug monitoring would be anticipated to be beneficial. However, the capability of most clinical laboratories to provide such a service is limited. Therefore, the clinician is forced to extrapolate the available pharmacodynamic and pharmacokinetic information available to select a dosage regimen. Due to the lack of published literature on the effects of critical illness and treatment on the pharmacokinetics of TMP/SMX, the clinician must attempt to estimate dosing requirements. Similarly, the lack of data on the impact of obesity on dosing requirements forces the clinician to base dosing on actual body weight to ensure achievement of desired drug concentrations. The urgency of obtaining effective concentrations in a patient who is critically ill from an infection warrants the use of doses larger than in patients with limited symptoms from the infection. By utilizing the limited available data on pharmacokinetics, pharmacodynamics, and potential for dose-related toxicities, the following doses are recommended for achieving the desired target concentrations for potential pathogens in critically ill patients.

For patients with Pneumocystis jovenii, Stenotrophomonas maltophilia, Burkholderia pseudomallei or Nocardia spp. infection - $15 \mathrm{mg} / \mathrm{kg} /$ day TMP IV or PO (with corresponding $75 \mathrm{mg} / \mathrm{kg} /$ day SMX).

(The drug could be given in two divided dosages based on the pharmacokinetics, but the relationship between Cmax concentrations and toxicity has been only evaluated in a limited non-critically ill population [7]. Whether the toxicity is more closely correlated with the Cmax or total exposure to the drugs is not known. To potentially minimize the impact of the Cmax on development of toxicities, the drug can be administered in smaller doses more frequently, three to four per day.)

For methicillin-resistant Staphylococcus aureus (MRSA) or extended-spectrum $\beta$-lactamase-producing (ESBL) Enterobacteriaceae - $160 \mathrm{mg}$ TMP IV or PO twice daily (with corresponding $800 \mathrm{mg}$ SMX).

For patient with renal impairment:

a) Measured or estimated creatinine clearance: Greater than $30 \mathrm{ml} / \mathrm{min}$ - full dose; 
Fifteen to $30 \mathrm{ml} / \mathrm{min}$ - half dose (the concentration of active SMX may be reduced, relying on TMP activity only);

Less than $15 \mathrm{ml} / \mathrm{min}$ - avoid drug if possible since the SMX metabolites will accumulate to potentially toxic concentrations unless dosage reduction in implemented, which would result in inadequate active SMX exposure.

b) Hemodialysis-dependency $-7.5 \mathrm{mg} / \mathrm{kg}$ after each four hour hemodialysis session (initial 24 to 48 hours at $15 \mathrm{mg} / \mathrm{kg} /$ day).

c) Continuous Ambulatory Peritoneal Dialysis - avoid drug if possible since the SMX metabolites will accumulate to potentially toxic concentrations unless dosage reduction in implemented, which would result in inadequate active SMX exposure.

d) Continuous Veno-venous Hemodiafiltration or Slow extended daily hemodialysis - $15 \mathrm{mg} / \mathrm{kg} /$ day TMP for Pneumocystis jovenii and equivalent infections; avoid underdosing with CVVHDF to avoid inadequate concentrations.

e) Liver Failure - no dosing adjustment needed.

\section{Conclusions}

Limited documentation of appropriate concentrations for treatment of critically ill patients forces the clinician to use available pharmacodynamic, toxicologic, and pharmacokinetics of both TMP and SMX in determining dosing regimens for critically ill patients considering organ of clearance impairment.

\begin{abstract}
Abbreviations
APACHE II: Acute Physiology and Chronic Health Evaluation II;

CAPD: Continuous Ambulatory Peritoneal Dialysis; CLSI: Clinical and Laboratory Standards Institute; Cmax: maximum concentration within the dosing interval; Cmin: minimum concentration within dosing interval; $\mathrm{CrCl}$ : creatinine clearance; CWHDF: Continuous Veno-venous Hemodiafiltration; ESBL: extended-spectrum $\beta$-lactamase-producing; IV: intravenous; MIC $_{90}$ : minimum inhibitory concentration adequate to inhibit 90\%; MRSA: methicillin-resistant Staphylococcus aureus; NAT2: N-acetyltransferase 2; PCP: Pneumocystis pneumonitis; PO: oral; SMX: sulfamethoxazole; T1/2: half-life; Tmax: time to reach maximum concentration; TMP: trimethoprim; $\mathrm{Vd}$ : volume of distribution.
\end{abstract}

\section{Competing interests}

The author declares no financial, professional, political, personal, religious, ideological, academic, intellectual, commercial or other relationship that would be a conflict of interest in the interpretation of any information related to TMP/SMX.

\section{Authors' contributions}

The sole author is responsible for all aspects of preparation, writing, and submission of this manuscript.

\section{Authors' information}

The author is a clinical pharmacist at St. Paul's Hospital in Vancouver, British Columbia where he has practiced for 25 years. The author is a Clinical Professor, Faculty of Pharmaceutical Sciences, University of British Columbia.

\section{Acknowledgments}

No funding was utilized in the preparation of this manuscript.

Received: 24 November 2013 Accepted: 24 March 2014

Published: 28 April 2014

\section{References}

1. Patel RB, Welling PG: Clinical pharmacokinetics of co-trimoxazole (trimethoprim-sulphamethoxazole). Clin Pharmacokinet 1980, 5:405-423.

2. Chin TWF, Vandenbroucke A, Fong IW: Pharmacokinetics of trimethoprimsulfamethoxazole in critically ill and non-critically ill AIDS patients. Antimicrob Agents Chemother 1995, 39:28-33.

3. Hess MM, Boucher BA, Laizure SC, Stevens RC, Sanders PL, Janning SW, Croce MA, Fabian TC: Trimethoprim-sulfamethoxazole pharmacokinetics in trauma patients. Pharmacotherapy 1993, 13:602-606.

4. Reeves DS, Wilkinson PJ: The pharmacokinetics of trimethoprim and trimethoprim/sulphonamide combinations, including penetration into body tissues. Infection 1979, 7(Supp4):S330-S341.

5. Vree TB, Hekster YA: Clinical pharmacokinetics of sulfonamides and their metabolites: an encyclopedia. Antibiot Chemother 1987, 37:100-113.

6. Stevens RC, Laizure SC, Sanders PL, Stein DS: Multiple-dose pharmacokinetics of 12 milligrams of trimethoprim and 60 milligrams of sulfamethoxazole per kilogram of body weight per day in healthy volunteers. Antimicrob Agents Chemother 1993, 37:448-452.

7. Steven RC, Laizure SC, Williams CL, Stein DS: Pharmacokinetics and adverse effects of $20 \mathrm{mg} / \mathrm{kg} /$ day trimethoprim and $100 \mathrm{mg} / \mathrm{kg} /$ day sulfamethoxazole in healthy adult subjects. Antimicrob Agents Chemother 1991, 35:1884-1890.

8. Baethke R, Golde G, Gahl G: Sulphamethoxazole/trimethoprim: pharmacokinetic studies in patients with chronic renal failure. Eur J Clin Pharmacol 1972, 4:233-240.

9. Spicehandler J, Pollock AA, Simberkoff MS, Rahal JJ: Intravenous pharmacokinetics and in vitro bactericidal activity of trimethoprimsulfamethoxazole. Rev Infect Dis 1982, 4:562-565.

10. Blaser J, Joos B, Opavil M, Luthy R: Variability of serum concentrations of trimethoprim and sulfamethoxazole during high dose therapy. Infection 1993, 21:206-209.

11. Siber GR, Gorham CC, Ericson JF, Smith AL: Pharmacokinetics of intravenous trimethoprim-sulfamethoxazole in children and adults with normal and impaired renal function. Rev Infect Dis 1982, 4:566-578.

12. Grose WE, Bodey GP, Loo TL: Clinical pharmacology of intravenously administered trimethoprim-sulfamethoxazole. Antimicrob Agents Chemothe 1979, 15:447-451.

13. Satler FR, Cowan R, Nielsen D, Ruskin J: Trimethoprim-sulfamethoxazole compared with pentamidine for treatment of Pneumocystis carinii pneumonia in the acquired immunodeficiency syndrome. Ann Intern Med 1988, 109:280-287.

14. Zelenitsky SA, lacovides H, Ariano RE, Harding GKM: Antibiotic combinations significantly more active than monotherapy in an in vitro infection model of Stenotrophomonas maltophilia. Diagn Microbiol Infect Dis 2005, 51:39-43.

15. Clinical and Laboratory Standards Institute: Methods for antimicrobial dilution and disk susceptibility testing of infrequently isolated or fastidious bacteria; approved guideline 2nd edition. 2010, 30(18, M45-A2).

16. Larruskain J, Idigoras P, Marimon JM, Perez-Trallero E: Susceptiblity of 186 Nocardia sp. isolates to 20 antimicrobial agents. Antimicrob Agents Chemother 2011, 55:2995-2998

17. Clinical and Laboratory Standards Institute: Performance standards for antimicrobial susceptibility testing; 23rd informational supplement. 2011, 32(3, M100-S22):1-182.

18. Matzke GR, Aronoff GR, Atkinson AJ, Bennett WM, Decker BS, Eckardt KU, Golper T, Grabe DW, Kasiske B, Keller F, Kielstein JT, Mehta R, Mueller BA, Pasko DA, Schaefer F, Sica DA, Inker LA, Ulmans JG, Murray P: Drug dosing considerations in patients with acute and chronic kidney disease - a clinical update from Kidney Disease: Improving Global Outcomes (KDIGO). Kidney Int 2011, 80:1122-1137.

19. Bergan T, Brodwall EK: Human pharmacokinetics of a sulfamethoxazoletrimethoprim combination. Acta Med Scand 1972, 192:483-492.

20. Craig WA, Kunin CM: Trimethoprim-sulfamethoxazole: pharmacodynamic effects of urinary $\mathrm{pH}$ and impaired renal function. Studies in humans. Ann Intern Med 1973, 78:491-497.

21. Reider VJ, Schartz DE: Pharmakokinetik der wirkstoffkombination trimethoprim + sulfamethoxazol bei leberkranken im vergleich zu gesunden. Arzneim-Forsch 1975, 25:656-666.

22. Kagaya H, Miura M, Niioka T, Saito M, Numakura K, Habuchi T, Satoh S: Influence of NAT2 polymorphisms on sulfamethoxazole pharmacokinetics in renal transplant recipients. Antimicrob Agents Chemother 2012, 56:825-829.

23. Slaughter RL, Myers CM, Reed MD, Kohli R, Brass C: The pharmacokinetics of sulfamethoxazole/trimethoprim during peritoneal and hemodialysis. Drug Intell Clin Pharm 1983, 17:440. Abstract. 
24. Nissenson AR, Wilson C, Holazo A: Pharmacokinetics of intravenous trimethoprim-sulfamethoxazole during hemodialysis. Am J Nephrol 1987 7:270-274

25. Papp CM, Nahata MC: Clinical use of trimethoprim/sulfamethoxazole during renal dysfunction. Ann Pharmacotherapy 1989, 23:646-654.

26. Ojo B, Wright N, Churchill D, Manuel MA, Walker S, Paton T: Trimethoprimsulfamethoxazole pharmacokinetics during continuous ambulatory peritoneal dialysis. Kidney Int 1986, 29:236. Abstract.

27. Halstenson CE, Blevins RB, Salem NG, Matzke GR: Trimethoprimsulfamethoxazole pharmacokinetics during continuous ambulatory peritoneal dialysis. Clin Nephrol 1984, 22:239-243.

28. Singlas E, Colin JN, Rottembourg J, Meessen JP, de Martin A, Legrain M, Simon P: Pharmacokinetics of sulfamethoxazole-trimethoprim combination during chronic peritoneal dialysis: effect of peritonitis. Eur J Clin Pharmacol 1982, 21:409-415.

29. Curkovic I, Luthi B, Franzen D, Ceschi A, Rudiger A, Corti N: Trimethoprim/ sulfamethoxazole pharmacokinetics in two patients undergoing continuous venovenous hemodiafiltration. Ann Pharmacother 2010, 44:1669-1672.

30. Clajus C, Kuhn-Velten WN, Schmidt JJ, Lorenzen JM, Pietsch D, Beutel G, Kielstein JT: Cotrimoxazole plasma levels, dialyzer clearance, and total removal by extended dialysis in a patient with acute kidney injury: risk of under-dosing using current dosing recommendations. BMC Pharmacol Toxicol 2012, 14:19

31. Jick H: Adverse reactions to trimethoprim-sulfamethoxazole in hospitalized patients. Rev Infect Dis 1982, 4:426-428

32. Dakin LE: Probable trimethoprim/sulfamethoxazole-induced higher-level gait disorder and nocturnal delirium in an elderly man. Ann Pharmacother 2009, 43:129-133.

33. Faria LC, Resende CC, Couto CA, Couto OFM, Fonseca LPC, Ferrari TCA: Severe and prolonged cholestasis caused by trimethoprim-sulfamethoxazole: a case report. Clinics 2009, 64:71-74.

34. Salkind AR: Acute delirium induced by intravenous trimethoprimsulfamethoxazole therapy in a patient with the acquired immunodeficiency syndrome. Human Exp Toxicol 2000, 19:149-151.

35. Chisholm-Burns MA, Patanwala AE, Spivey CA: Aseptic meningitis, hemolytic anemia, hepatitis, and orthostatic hypotension in a patient treated with trimethoprim-sulfamethoxazole. Am J Health-Syst Pharm 2010, 67:123-127.

36. Perazella MA: Trimethoprim-induced hyperkalaemia: clinical data, mechanism, prevention and management. Drug Saf 2000, 22:227-236.

37. Tse $W$, Singer C, Dominick D: Acute fulminant hepatic failure caused by trimethoprim-sulfamethoxazole. Infect Dis Clin Pract 2000, 9:302-303.

38. Strevel EL, Kuper A, Gold WL: Severe and protracted hypoglycaemia associated with co-trimoxazole use. Lancet Infect Dis 2006, 6:178-182

39. Cryst C, Hammar SP: Acute granulomatous interstitial nephritis due to co-trimoxazole. Am J Nephrol 1988, 8:483-488.

40. Capra C, Mario Monza G, Meazza G, Ramella G: Trimethoprim-sulfamethoxazoleinduced aseptic meningitis: case report and literature review. Intens Care Med 2000, 26:212-214.

41. Koirala J: Trimethoprim-sulfamethoxazole-induced methemoglobinemia in an HIV-infected patient. Mayo Clin Proc 2004, 79:829-830.

42. Hemstreet BA: Antimicrobial-associated renal tubular acidosis. Ann Pharmacother 2004, 38:1031-1038.

43. Gerber P, Brown G, Grant G: Co-trimoxazole induced multi-organ failure. Can J Hosp Pharm 1997, 50:277-280.

44. Dib EG, Bernstein S, Benexch C: Multifocal myoclonus induced by trimethoprim-sulfamethoxazole therapy in a patient with Nocardia infection N Engl J Med 2004, 350:88-89.

45. Brett AS, Shaw SV: Simultaneous pancreatitis and hepatitis associated with trimethoprim-sulfamethoxazole. Amer J Gastroenterol 1999, 94:267-268.

46. Weis S, Karagulle D, Kornhubr J, Bayerlein K: Cotrimoxazole-induced psychosis: a case report and review of the literature. Pharmacopsychiatry 2006, 39:236-237.

47. Patel JS, Scheiner ED: Acute parotitis induced by trimethoprim/ sulfamethoxazole. Ear Nose Throat J 2011, 90:E22-E24.

48. Schwarz A, Perez-Canto A: Nephrotoxicity of antiinfective drugs. Int J Clin Pharm Ther 1998, 36:164-167.

49. Wanat KA, Anadkat MJ, Klekotka PA: Seasonal variation of Stevens-Johnson syndrome and toxic epidermal necrolysis associated with trimethoprimsulfamethoxazole. J Am Acad Dermatol 2009, 60:589-594.

50. Slavik RS, Ryback MJ, Lerner SA: Trimethoprim-sulfamethoxazole-induced tremor in a patient with AIDS. Ann Pharmacother 1998, 32:189-192.
51. Yamreudeewong W, Fosnocht BJ, Weixelman JM: Severe thrombocytopenia possibly associated with TMP/SMX therapy. Ann Pharmacother 2002, 36:78-82

52. Lopez JA, Harold JG, Rosenthal MC, Oseran DS, Schapira JN, Peter T: QT Prolongation and torsades de pointes after administration of trimethoprim-sulfamethoxazole. Amer J Cardiol 1987, 59:376-377.

53. Hitchings $\mathrm{GH}$ : Mechanisms of action of trimethoprim-sulfamethoxazole I and II. J Infect Dis 1973, 128(Suppl):S433-S441.

54. Burman LG: The antimicrobial activities of trimethoprim and sulfonamides. Scand J Infect Dis 1986, 18:3-13.

55. Close SJ, McBurney CR, Garvin CG, Chen DC, Martin SJ: Trimethoprimsulfamethoxazole activity and pharmacodynamics against glycopeptideintermediate Staphylococcus aureus. Pharmacotherapy 2002, 22:983-989.

56. Lewis EL, Anderson JD, Lacey RW: A reappraisal of the antibacterial action of cotrimoxazole in vitro. J Clin Pathol 1974, 27:87-91.

57. Craig WA, Andes D: Pharmacokinetics and pharmacodynamics of antibiotics in otitis media. Ped Infect Dis J 1996, 15:255-259.

58. Burman LG: Significance of the sulfonamide component for the clinica efficacy of trimethoprim-sulfonamide combinations. Scand J Infect Dis 1986, 18:89-99.

59. Lacey RW, Rogerson JG, Stokes A: Antimicrobial effects of trimethoprim and sulphadiazine in infected urine and blood. J Med Microbiol 1980, 13:121-132.

60. Cheng AC, McBryde ES, Wuthiekanun V, Chierakul W, Amornchai P, Day NPJ, White NJ, Peacock SH: Dosing regimens of cotrimoxazole (trimethoprimsulfamethoxazole) for melioidosis. Antimicrob Agents Chemother 2009, 53:4193-4199.

61. Tripodi MF, Durante-Mangoni E, Fortunato R, Cuccurullo S, Mikami Y, Farina C, Utili R: In vitro activity of multiple antibiotic combinations against Nocardia: relationship with a short-term treatment strategy in heart transplant recipients with pulmonary nocardiosis. Transpl Infect Dis 2011, 13:335-343.

62. Hughes WT, Feldman S, Sanyal SK: Treatment of Pneumocystis carinii pneumonitis with trimethoprim-sulfamethoxazole. Can Med Assoc J 1976, 112(Suppl):47S-50S.

63. Hughes WT, Feldman S, Chaudhary SC, Ossi MJ, Cox F, Sanyal SK: Comparison of pentamidine isethionate and trimethoprim-sulfamethoxazole in the treatment of Pneumocystis carinii pneumonia. J Pediatr 1978, 92:285-291.

64. Lau WK, Young LS: Trimethoprim-sulfamethoxazole treatment of Pneumocystis carinii pneumonia in adults. N Eng J Med 1976, 295:716-718.

65. Winston DJ, Lau WK, Gale RP, Young LS: Trimethoprim-sulfamethoxazole for the treatment of Pneumocystis carinii pneumonia. Ann Intern Med 1980, 92:762-769.

66. Gales AC, Jones RN, Forward KR, Linares J, Sader HS, Verhoef J: Emerging importance of multidrug-resistant Acinetobacter species and Stenotrophomonas maltophilia as pathogens in seriously ill patients: geographic patterns, epidemiological features, and trends in the SENTRY antimicrobial surveillance program (1997-99). Clin Infect Dis 2001, 32(Suppl 2):S104-S113.

67. Vartivarian S, Anaissie E, Bodey G, Sprigg H, Rolston K: A changing pattern of susceptibility of Xanthomonas maltophilia to antimicrobial agents: implications for therapy. Antimicrob Agents Chemother 1994, 38:624-627.

68. Muder RR: Optimizing therapy for Stenotrophomonas maltophilia. Semin Resp Crit Care Med 2007, 28:672-677.

69. Inglis TJJ: Treatment of melioidosis. Pharmaceuticals 2010, 3:1296-1303.

70. Chusri S, Hortiwakul T, Charoenmak B, Silpapojakul K: Outcomes of patients with melioidosis treated with cotrimoxazole alone for eradication therapy Am J Trop Med Hyg 2012, 87:927-932.

71. Broome Uhde K, Pathak S, McCullum I, Jannat-Khah DP, Shadomy SV, Dykewicz CA Clark TA, Smith TL, Brown JM: Antimicrobial-resistant Nocardia isolates, United States, 1995 to 2004. Clin Infect Dis 2010, 51:1445-1448.

72. Grim SA, Rapp RP, Martin CA, Evans ME: Trimethoprim-sulfamethoxazole as a viable treatment option for infections caused by methicillin-resistant Staphylococcus aureus. Pharmacotherapy 2005, 25:253-264.

73. Goldberg E, Bishara J: Contemporary unconventional clinical use of co-trimoxazole. Clin Microbiol Infect 2012, 18:8-17.

74. Goldberg E, Paul M, Talker O, Samara Z, Raskin M, Hazzan R, Leibovici L, Bishara J: Co-tromoxazole versus vancomycin for the treatment of methicillin-resistant Staphylococcus aureus bacteraemia: a retrospective cohort study. J Anttimicrob Chemother 2010, 65:1779-1783.

75. Campbell ML, Marchaim D, Pogue JM, Sunkara B, Bheenreddy S, Bathina P, Pulluru H, Chugh N, Wilson MN, Moshos J, Ku K, Hayakawa K, Martin ET, Lephart PR, Rybak MJ, Kaye KS: Treatment of methicillin-resistant Staphylococcus aureus infections with a minimal inhibitory concentration of $2 \mathrm{mcg} / \mathrm{ml}$ to vancomycin: old (trimethoprim/sulfamethoxazole) versus new (daptomycin or linezolid) agents. Ann Pharmacother 2012, 46:1587-1597. 
76. Lemair S, Kosowska-Shick K, Appelbaum PC, Glupczynski Y, Van Bambeke F, Tulkens PM: Activity of moxifloxacin against intracellular communityacquired methicillin-resistant Staphylococcus aureus: comparison with clindamycin, linezolid and co-trimoxazole and attempt at defining an intracellular susceptibility breakpoint. J Antimicrob Chemother 2011, 66:596-607.

77. Pitout JDD, Laupland KB: Extended-spectrum B-lactamase-producing Enterobacteriaceae: an emerging public-health concern. Lancet Infect Dis 2008, 8:159-166.

78. Simner PJ, Zhanel GG, Pitout J, Tailor F, McCracken M, Mulvey MR, Lace-Wiens PFS, Adam HJ, Hoban DJ: Prevalence and characterization of extended-spectrum beta-lactamase- and AmpC beta-lactamaseproducing Escherichia coli: results of the CANWARD 2007-9 study. Diagn Microbiol Infect Dis 2011, 69:326-334.

doi:10.1186/2110-5820-4-13

Cite this article as: Brown: Cotrimoxazole - optimal dosing in the critically ill. Annals of Intensive Care 2014 4:13.

\section{Submit your manuscript to a SpringerOpen ${ }^{\circ}$ journal and benefit from:}

- Convenient online submission

- Rigorous peer review

- Immediate publication on acceptance

- Open access: articles freely available online

- High visibility within the field

- Retaining the copyright to your article 